\title{
For Promoting Remediation of Contaminated Area; Principle of Remediation Methods
}

\section{-From Tests at Date-city and Iitate-mura in Fukushima Prefecture-}

\author{
Radiation Safety Forum (NPO), Zenko Yoshida
}

\begin{abstract}
The decontamination of areas affected by the disaster that occurred at the Fukushima Daiichi Nuclear Power Plant will gather momentum with the full enforcement of the Act on Special Measures concerning the Handling of Pollution by Radioactive Materials on January 1, 2012. This work must be carried out swiftly to help evacuees return to their homes as soon as possible. Although some technologies still need to be developed, the basic decontamination methods have been established based on earlier demonstration tests and the like. This commentary explains the principles of the main decontamination methods based on tests conducted mainly by the Radiation Safety Forum, a Japanese non-profit organization.
\end{abstract}

\section{Introduction}

The Great East Japan Earthquake triggered a disaster at the Fukushima Daiichi Nuclear Power Plant. As a result, a large amount of radioactive cesium and other such radionuclides was released into the environment, thereby contaminating vast areas. The inevitable first step that is required to help restore the lives of evacuees is the removal of radioactive cesium from their living areas. No other options are available. In late August 2011, the Japanese government enacted the Act on Special Measures concerning the Handling of Pollution by Radioactive Materials. The decontamination work will gather momentum with the full enforcement of this act on January 1,2012. The work must be carried out swiftly to help evacuees return to their homes as soon as possible. To this end, optimal decontamination methods must be chosen by taking into consideration various factors, including not only the type, amount, properties, and radioactivity level of the intended target, but also the desired efficiency, the amount of resultant waste, the necessary costs, the duration, and the safety of workers.

Since May 2011, the Radiation Safety Forum, a Japanese non-profit organization, has conducted decontamination tests on radioactive cesium in Date City and Iitate Village (Iitate mura), Fukushima Prefecture, in partnership with the Japan Atomic Energy Agency (JAEA), local governments, private companies, and other organizations. The entire village of Iitate has been 
designated as a deliberate evacuation area. Decontamination tests were conducted by about 60 experts over the course of 4 days (May 19-20 and 26-27) mainly on houses and farmland in the Nagadoro District, which had a particularly high air dose rate in Iitate. In addition, from early July to the end of September, tests were conducted on schools, settlements, peach orchards, community forests, and other parts of Date City, given that it has over 100 households in specific spots recommended for evacuation in the districts of Shimo-oguni and Tsukidate. Notably, the decontamination of a primary school and a preschool in the Tominari District that took place over the course of 11 days (July 2-17) was carried out by school employees, local stakeholders, parents, and many other volunteers as well as 370 experts.

This commentary presents the optimal decontamination methods identified based on previously conducted tests. It then explains the principles of these methods to facilitate the selection of the appropriate decontamination method in practice.

\section{Principles of Decontamination Methods}

\section{Scraping of Surface Soil}

The predominant decontamination target is the surface soil of this vast extent of land. The intended use of this land is diverse, ranging from residential, industrial, agricultural land and land designated for public facilities to forests and so on. Regardless of the various different land uses, radioactive cesium is commonly concentrated in the top part of the contaminated soil. This commonality has significant implications for the decontamination methods described in this section.

More specifically, the radioactive cesium that was deposited on the ground surface in midMarch 2011 was immediately captured when it bonded with the clay minerals present in the surface soil. Once captured, the cesium became extremely stable, so it remained near the ground surface without migrating inside the soil or dissolving into water as cesium ions. This stability is a result of the strong bonding of positively charged cesium ions in the cavities and layers of negatively charged clay minerals. The bonding strength is increased because the sizes of these cavities and layers are similar to the size of cesium ions in an aqueous solution (diameter: approx. $5 \times 10^{-8} \mathrm{~cm}$ ).

Figure 1 presents data on the vertical distribution of radioactive cesium in the surface soil of a pasture located in the Nagadoro District of Iitate Village (sampled and analyzed on May 19 and 20,2011). Almost all of the radioactive cesium is concentrated in an area ranging from the ground surface to a depth of approximately $3 \mathrm{~cm}$. This finding was not unique to pastures. A high concentration of radioactive cesium at a depth ranging from a few to five centimeters has also been confirmed for not only farmland used for greenhouses and paddies in the same district, but also land used for primary schools and orchards in Date City.

Given the behavior of cesium in soil, the most efficient way to decontaminate soil is to scrape off the surface soil. Scraping must be performed carefully to remove as thin a layer as possible and thereby minimize the amount of waste produced. Ideally, the scraping work should be carried out manually using hoes or shovels. For instance, the decontamination of grassland and gravel roads at a primary school in Date City was carried out by many parents, local residents, and volunteers using this equipment. This labor force enabled the decontamination work to be performed quickly throughout the vast school premises. To prevent this manual work from stirring up sand or dust, the PIC method (to be explained later) can be employed or other measures can be implemented to at least suppress any sand or dust scattering 


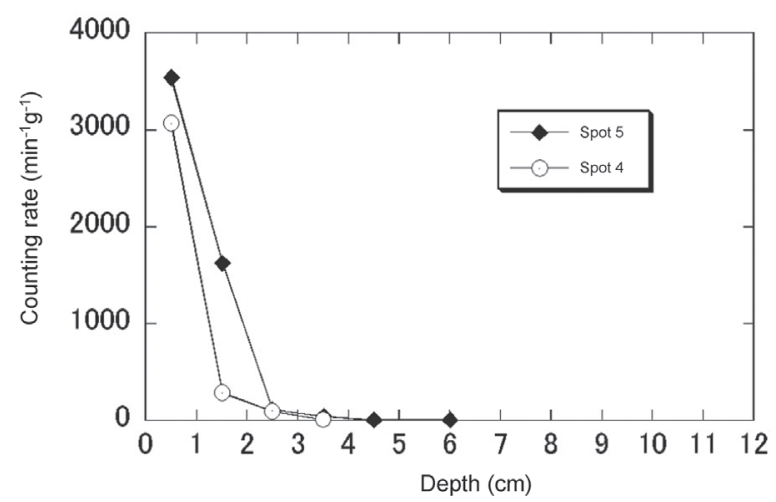

Figure 1 Vertical distribution of radioactive cesium in the surface soil of a pasture ${ }^{1)}$

(e.g., by sprinkling water).

As an alternative to the manual approach, a power shovel was deployed to remove the surface soil on the premises of a private house located in Date City. This highly efficient means of scraping off over $10 \mathrm{~cm}$ of surface soil produced double the amount of soil waste. For this mechanical approach to be employed, the machinery would have to be modified or developed so that it could scrape off a much thinner layer of surface soil.

However, heavy machinery can prove exceptionally effective in certain places. For instance, specialized machines for removing grass in a pasture probably offer a more effective means of decontaminating places with a relatively even growth of grass.

Scraping of the surface soil was also tried in another test conducted in a peach orchard located in Date City. While the surface soil is being removed in an orchard such as this, special attention must be paid to avoid hurting any tree roots that may extend near the surface. Ideally, this should be done by performing manual scraping so that as thin a layer as possible can be removed with precision. The combined use of a vacuum suction unit and a gardening shovel to remove surface soil with a thickness of $2 \mathrm{~cm}$ and $5 \mathrm{~cm}$ achieved a decontamination efficiency of around $40 \%$ and $80 \%$, respectively. Considering how vast the target area is, specialized machinery probably needs to be developed for scraping off the surface soil in orchards.

The polyion complex (PIC) method ${ }^{1)}$ was tried for the removal of a thin layer of surface soil. This method involves spraying an aqueous solution of a mixture of polymer cations and polymer anions on the ground surface and allowing it to soak into soil before solidifying into polyion complexes (PICs). These PICs and the surface soil are then scraped off together. One advantage of this method is that a relatively small amount of PIC (e.g., 2 wt $\%$ of soil) is sufficient to soak into the soil and solidify the surface layer. Figure 2 shows slices of surface soil that was solidified using the PIC and then scraped off from farmland covered by a greenhouse. Another advantage of the PIC method is its ability to prevent dust from being stirred up while the surface soil is being scraped off. In a test conducted on relatively dry dust-producing farmland for greenhouses, the adoption of the PIC method reduced the level of airborne soil dust to half or even less than one-third the usual level.

The effectiveness of the PIC method was also demonstrated in tests conducted on private houses and farmland in Iitate Village and an assembly hall in Date City. These tests all proved that the PIC method provides an efficient means of removing radioactive cesium from the ground surface.

As an example, the results from the decontamination tests conducted using the PIC method 


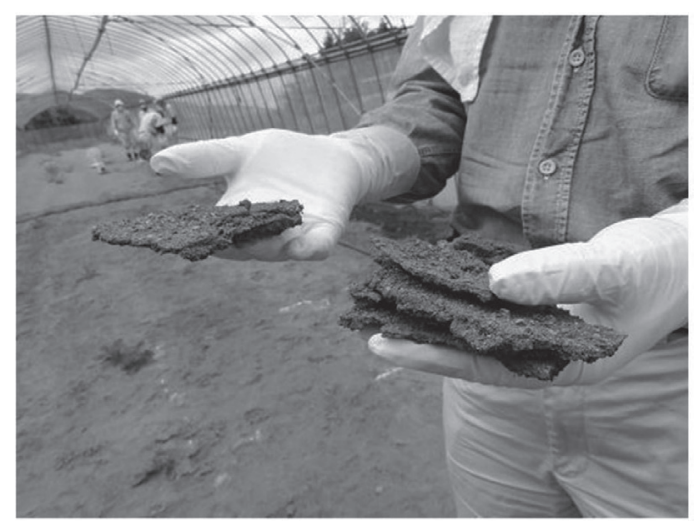

Figure 2 Slices of soil scraped off at farmland for greenhouses after being solidified using polyion complexes for decontamination ${ }^{1)}$

on farmland in Iitate Village are presented below. Before the decontamination, the radioactivity concentration measured using GM survey meters on pastures, paddies, and farmland for greenhouses stood at $1.7 \times 10^{4} \mathrm{cpm}, 4.3 \times 10^{4} \mathrm{cpm}$, and $1.6 \times 10^{4} \mathrm{cpm}$, respectively. At all of these test sites, between 80 and $95 \%$ of radioactive cesium was removed by scraping off the surface soil using the PIC method.

Many other methods have also been proposed as alternatives to scraping off the surface soil, such as employing adsorbents or extractants to elute the cesium contained in the soil into an aqueous solution in the form of ions. As mentioned earlier, however, it is generally difficult to dissolve the cesium in the soil into an aqueous solution because the cesium is extremely stable. Hot acids or aqueous solutions can hasten the cesium elution from soil of course, but that is not a realistic method for decontaminating a vast area of land.

\section{Removal of Thin Slices of Concrete and Asphalt Surfaces}

Radioactive cesium that has contaminated concrete or asphalt surfaces bonds tightly with the clay mineral particles contained in these base materials. For this reason, radioactive cesium is concentrated near the surface. As is the case when it is present in soil, the radioactive cesium does not migrate very much inside the concrete or asphalt and it does not dissolve into an aqueous solution. For this reason, the best decontamination method involves slicing off a thin layer from the surface of the concrete or asphalt with a thickness of $1 \mathrm{~mm}$ or less by using specialized machinery.

Various machines have been tried for the decontamination of asphalt and concrete by slicing off thin layers from the surface. Of these machines, a shot blast, which chips away the surface of the target by bombarding it with iron balls that have a diameter of around $1 \mathrm{~mm}$ at a high speed (Figure 3), proved to be the most effective option. Tests demonstrated that this machine could chip away a layer with a thickness of between 0.1 and $0.2 \mathrm{~mm}$ from the asphalt surface in one sweep, thereby enabling about 85 to $90 \%$ of the radioactive cesium to be removed. When two sweeps were performed, the removal performance exceeded $90 \%$.

However, the removal performance of a shot blast was reduced to between about 50 and $70 \%$ in cracks of various sizes on asphalt roads. A higher performance can be gained by using a shot blast in combination with a vacuum suction unit to remove the sediments and impurities present in these cracks. It is also desirable to inject filler into the decontaminated cracks to prevent any recontamination. 


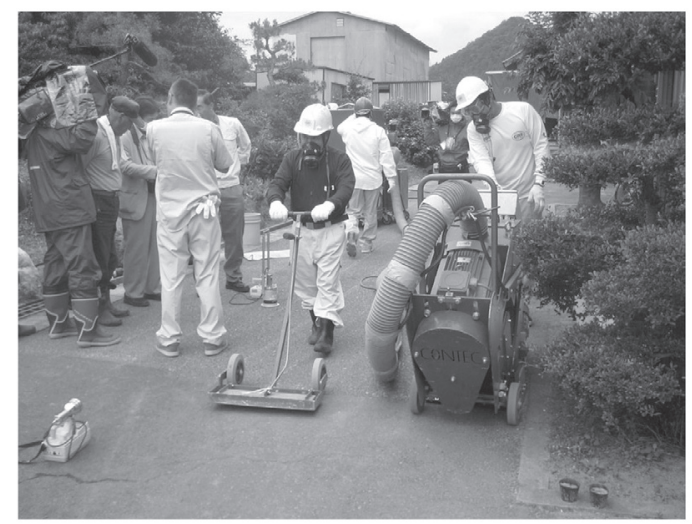

Figure 3 A shot blast for chipping away the surface of asphalt and concrete (photo courtesy of ATOX Co., Ltd.)

Shot blasts also offer an effective means of decontaminating concrete surfaces. Grinders (also known as "concrete shavers") are useful for decontaminating targets in narrow spaces, such as concrete stairs. A sufficient removal performance could be achieved by grinding away a thin layer (thickness: approx. $0.5 \mathrm{~mm}$ ) from the surface of the concrete. During any blasting operation, a dust collector should be connected to the shot blast to prevent the scattering of concrete particles.

As an example, the results of tests conducted using a machine to grind away layers from the surface of asphalt and concrete in a primary school located in Date City are presented below. Before the decontamination, the air dose rate was within the range of 5 to $8.5 \mu \mathrm{Sv} / \mathrm{h}$ on an asphalt slope leading to the school building, 0.7 to $1.6 \mu \mathrm{Sv} / \mathrm{h}$ in the asphalt square located in front of the school building, and 1.2 to $1.8 \mu \mathrm{Sv} / \mathrm{h}$ on the concrete stairs leading from the square down to the ground. After the decontamination, the air dose rate was reduced in almost all of the test spots. For instance, the asphalt slope leading to the school, which had the highest air dose rate prior to decontamination, registered a significant drop to 0.6 to $1.0 \mu \mathrm{Sv} / \mathrm{h}$ in all of the test spots.

Aside from the mechanical chipping of asphalt surfaces, various chemical decontamination methods were also tested with the aim of dissolving the radioactive cesium by using various acid or salt solutions. However, even the most effective methods -which involved using hydrochloric acid $(1 \mathrm{~mol} / \mathrm{L})$, nitric acid $(1 \mathrm{~mol} / \mathrm{L})$, or sodium citrate solution $(1 \mathrm{~mol} / \mathrm{L})-$ were only able to remove a maximum of $20 \%$ of the radioactive cesium (Naganawa et al., private communication).

\section{Water Blast Cleaning}

Radioactive cesium tends to be loosely deposited as dust on the roofs and walls of buildings. Blast cleaning of roof tiles, gutters, and wall surfaces with pressurized water is a relatively simple means of washing away radioactive cesium along with the dust. This method is an effective option for decontaminating large areas, and it is the best option for performing decontamination work in elevated places. In many cases, however, the radioactive cesium becomes firmly adsorbed by the tile surface once it has been deposited, so blast cleaning alone cannot remove the radioactive cesium sufficiently well. Consequently, the surface must be brushed with a cleaner or undergo another special treatment, especially if a high concentration 
of radioactive cesium has been deposited on tiles. During any cleaning operation, additional measures must be taken to minimize the scattering of misty droplets containing radioactive cesium and to prevent the radioactive cesium from dispersing by managing the channels of wastewater.

Water blast cleaning proved an effective means of decontaminating the rooftops and balconies of school buildings. For instance, nearly $90 \%$ of the radioactive cesium was removed by washing away moss, sludge, and fallen leaves from the balconies.

In addition, water blast cleaning removed over $90 \%$ of the radioactive cesium from the rubber mats located along the sides of pools after a commercially available acidic cleaner had been applied and they had been brushed using a scrubbing brush, polisher, and the like. Water blast cleaning also proved an effective means of decontaminating swimming pool gutters after the moss, sediment, dead leaves, and the like had been removed using a vacuum suction unit.

However, water blast cleaning combined with the application of various cleaners and the scrubbing of the surface with a polisher did not prove sufficiently effective for the decontamination of road surfaces paved with asphalt or concrete.

\section{Direct Removal of Contaminants}

If feasible, the most effective and reliable decontamination method is to remove the radiation sources directly. Numerous examples of the application of this method are available. The results from some decontamination tests conducted in Iitate Village and Date City are presented below to provide examples.

Prior to decontamination carried out in a test at a private house in Iitate Village, the state of the radiation sources was examined. The radiation sources were found to mainly meet the following conditions: (1) deposited on roof tiles and building surfaces; (2) deposited on the ground surface at the premises; (3) deposited in the sludge that had piled up in the gutter; (4) concentrated in the soil around a water collecting pit leading from the gutter; (5) deposited on fallen leaves from cedar and other trees as well as on the leaf mulch in the backyard; and (6) deposited on the surface of leaves from evergreens, such as cedar and fir trees, around the house. The best decontamination method for radiation sources (3) to (6) is their direct removal.

As much as possible of any sediment in a gutter or sludge in a water collecting pit should be removed. For instance, such work removed between 75 and $90 \%$ of the radioactivity from the gutter (the radioactivity concentration on the gutter surface as measured with a GM survey meter dropped from between $4 \times 10^{4}$ and $5 \times 10^{4} \mathrm{cpm}$ to less than $1 \times 10^{4} \mathrm{cpm}$ after the removal). To prevent the sediment and sludge being stirred up as dust, it is desirable to solidify them using the aforementioned PIC method before their removal.

Fallen leaves from cedar and other trees should also be removed from the backyard. The radioactivity concentration was relatively high (between $1.5 \times 10^{4}$ and $3 \times 10^{4} \mathrm{cpm}$ in one spot) in the backyard and the slope beside it where weeds were growing on the leaf mulch. In this area, between 60 and $80 \%$ of the radioactivity was removed by the complete removal of leaf mulch and weeds, followed by the scraping of the surface soil.

In the backyard of a private house in Iitate Village, leaves were sampled from a fir tree. Autoradiography was performed to check for the presence of radioactive cesium in the sample and examine its distribution. The distribution results are shown in Figure 4. The darker black areas indicate a higher concentration of radioactive cesium. The results indicated an almost homogenous deposition of radioactive cesium on leaves and branches (see Reference 2 for 


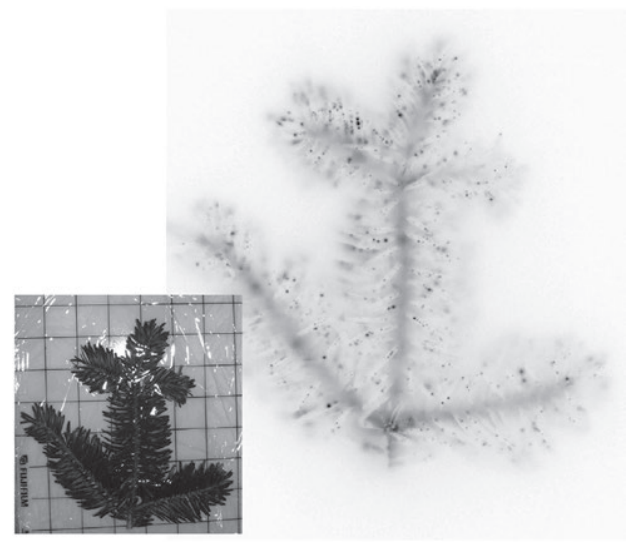

Figure 4 Autoradiography of fir leaves ${ }^{2)}$

Black spots in the image indicate the deposited radioactive cesium.

details). The radioactive cesium deposited on the surface of leaves from evergreens, such as cedar and fir trees, becomes firmly bonded, so it cannot be removed simply by washing it away with water and the like. Consequently, pruning and felling must be performed to reduce this radioactivity.

Prior to the performance of a decontamination test at a private house in Iitate Village, the dose rates were measured at nine spots, including the entrance to the main building, a Japanese-style room, the kitchen, and a corridor. The measured dose rates were significantly high across the board within the range of 4 to $10 \mu \mathrm{Sv} / \mathrm{h}$. Especially, the relatively higher measurements that were obtained around the external walls of the room facing the backyard $(6.5-9.6 \mu \mathrm{Sv} / \mathrm{h})$ suggest that sources in the backyard made a large contribution. In addition, a high dose rate was observed around the corridor near the water collecting pit leading from the gutter. Measurements obtained inside the main building demonstrated that decontamination reduced the dose rates in the room facing the backyard and the corridor near the rainwater collecting pit from their previously high levels. The dose rates in all of the nine spots converged to a level between 3.0 and $4.3 \mu \mathrm{Sv} / \mathrm{h}$. However, further decontamination must be carried out because this outcome is not yet sufficient. A further reduction in the dose rates could possibly be made by felling a wide range of cedar and fir trees around the house (e.g., within $50 \mathrm{~m}$ of the house).

The results of a decontamination test conducted in a community forest located in Date City are as follows. In mid-March 2011, the leaves on deciduous trees had not yet emerged, so most of the fallen radioactive cesium was deposited on the fallen leaves from last autumn or the leaf mulch. As of autumn 2011, the most effective method for decontaminating deciduous trees was the removal of the fallen leaves from last autumn and the leaf mulch. The decontamination test conducted in October 2011 in a community forest in Date City verified that simply clearing fallen leaves removes between 30 and $60 \%$ of the radioactivity. This decontamination performance could be further enhanced by scraping off the soil underneath the fallen leaves and the leaf mulch. Meanwhile, the leaves that emerged on deciduous and broadleaved trees after spring 2011 do not require decontamination because almost no radioactive cesium adhered to them.

In contrast, the decontamination performance of simply removing fallen leaves from evergreens (mainly in cedar forests) was as low as 10\%. It turned out that scraping off a layer with a thickness of around $5 \mathrm{~mm}$ from the surface of the soil was necessary to boost the performance 
to nearly $90 \%$. As mentioned earlier, leaves on evergreens are highly contaminated, so they require pruning, felling, or similar measures.

\section{Water Purification and Discharge}

Swimming pools at schools were filled with water from the previous autumn (2010). The bottoms of the pools were full of piles of dust and sludge from fallen leaves and the like. In the water, blue-green algae were flourishing. The radioactive cesium that had fallen on the water of these swimming pools was deposited in either the sludge or the algae, causing them to bond, or formed free ions in the water (Figure 5). Taking the swimming pool at the Tominari Elementary School in Date City as an example, the average radioactive cesium concentration (of the sampled nearly homogenous water with the radioactive cesium having combined with the entire pool after stirring the water) was found to be about $650 \mathrm{~Bq} / \mathrm{kg}$. The measurements taken revealed that about $70 \%$ of the radioactive cesium had been deposited in the sludge, about $10 \%$ had been deposited on the algae, and about $20 \%$ had dissolved in the water as cesium ions.

An effective way to treat the water in swimming pools ${ }^{3)}$ is to purify and drain away the upper portion that contains mainly both algae and free cesium ions before collecting the sludge on the bottom. The purification method used for the upper portion can be explained as follows. First, the upper portion of the water in the swimming pool is pumped into a polyethylene tank with a capacity of one ton. A small amount of zeolite powder is added, followed by an appropriate amount of a coagulant (polyaluminum chloride solution) to coagulate and precipitate the sedimentation of the algae and the zeolite powder. Once the water from the supernatant in the tank has been pumped away, the deposits are collected by filtration using a hemp sack or the like and the filtrated water is drained. After that, the sludge on the bottom of the pool is collected and filtrated using a hemp sack or the like, and finally the decontaminated water is drained away.

After the water had been treated using the above method, the swimming pools were filled

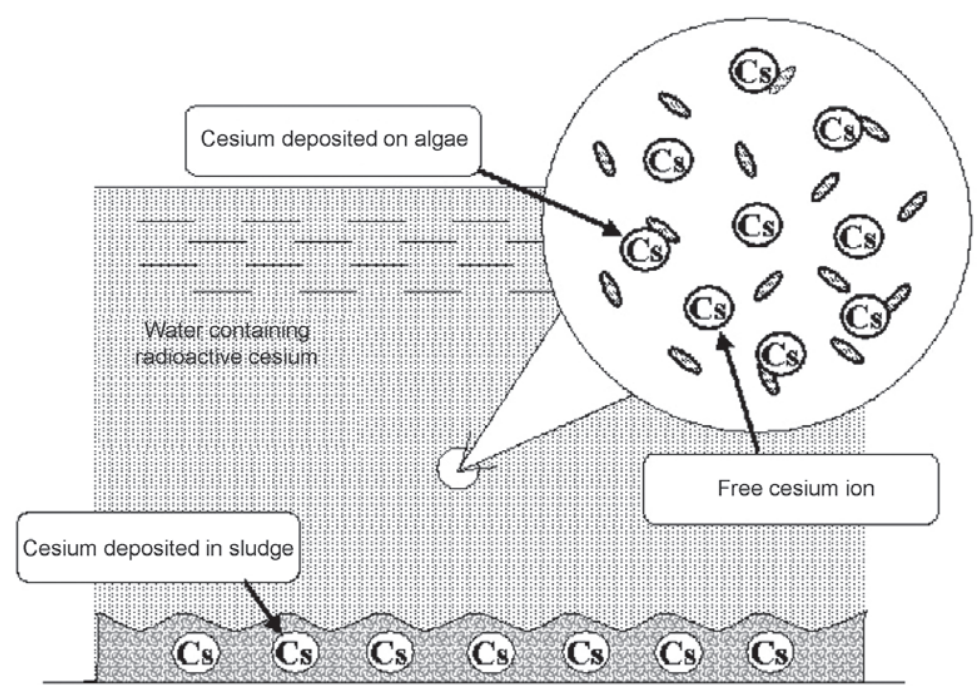

Figure 5 Chemical forms of radioactive cesium in the water of a swimming pool 
with tap water for 1 or 2 days. Subsequent measurements of the water verified that the radioactivity concentration had been reduced to under the detection limit (ca. $10 \mathrm{~Bq} / \mathrm{kg}$ ). The decontamination of the sides of the pools reduced the air dose rate from between 2 and $8 \mu \mathrm{Sv} / \mathrm{h}$ to between 0.7 and $0.8 \mu \mathrm{Sv} / \mathrm{h}$, thereby enabling the swimming pools to be used.

This water treatment method can be applied not only to swimming pools, but also to any kind of puddles. The same method was employed for the decontamination of a lotus pond next to the school building at Tominari Elementary School. This method can probably be applied in the decontamination of holding ponds scattered around farming areas.

\section{Conclusions}

This commentary explains the principles of basic decontamination technologies. The appropriate method must be employed according to the intended target. Some technologies and machines must be developed urgently. These development needs should be addressed immediately to keep pace with decontamination efforts. The waste produced from the decontamination work should be managed and disposed of in an appropriate manner. On October 29, 2011, the Ministry of the Environment presented the basic concept for interim storage facilities. It is hoped that the construction of temporary waste storage yards and interim waste storage facilities will be promoted, and then it will hasten the decontamination work in affected areas.

The content of this commentary is based on the results of decontamination tests conducted in Date City and Iitate Village under the coordination of Dr. Shunichi Tanaka, Vice President of the Radiation Safety Forum. The author would like to extend his gratitude to the many people who helped conduct these tests, including the following: Mr. Tatsuya Fukuda, Mr. Junichiro Tada, and their colleagues from Chiyoda Technol Corporation; Mr. Kaoru Kashima, Mr. Hiroshi Saito, and their colleagues from ATOX Co., Ltd.; Dr. Noriyuki Kumazawa (Ibaraki University); Dr. Hirochika Naganawa, Dr. Toshihiko Ohnuki (JAEA), and their fellow research group members; employees of the Date City Office; members of COOP Fukushima; members of the local community; and volunteers from many different parts of Japan.

\section{References}

1) H. Naganawa, N. Kumazawa, H. Saito et al.: Removal of Radioactive Cesium from Surface Soil Solidified Using Polyion Complex as a Solidifying Agent-Rapid Communication for Decontamination Tests at Iitate-mura in Fukushima Prefecture [in Japanese], Transactions of the Atomic Energy Society of Japan, 10, 227-234 (2011).

2) F. Sakamoto, T. Ohnuki, N. Kozai et al.: Local Area Distribution of Fallout Radionuclides from Fukushima Daiichi Nuclear Power Plant Determined by Autoradiography Analysis [in Japanese], Transactions of the Atomic Energy Society of Japan, 11, 1-7 (2012).

3) Guide for the Decontamination of Swimming Pools at Schools [in Japanese], JAEA website (http:// www.jaea.go.jp//fukushima). 